\title{
Evaluación in vitro de las actividades antimicrobiana, antioxidante y protectora del ADN, de un extracto etanólico de romero (Rosmarinus officinalis L.)
}

\section{In vitro evaluation of the antimicrobial, antioxidant and DNA protective activities of an ethanolic extract of rosemary (Rosmarinus officinalis L.)}

\author{
Cecchini Maria Eugenia ${ }^{1}$, Roma dardo Andrés ${ }^{1}$, Pussetto lucía ${ }^{1}$, Iglesias Delvis ${ }^{1}$, \\ Basualdo María Claudia ${ }^{2}$, Aiassa delia Elba ${ }^{3}$, Mañas Torres Fernando Javier ${ }^{1^{*}}$
}

1. Laboratorio de Farmacología, Facultad de Agronomía y Veterinaria. 2. Laboratorio de Salud Pública, Facultad de Agronomía y Veterinaria. 3. Laboratorio de Genética y Mutagénesis Ambiental, Facultad de Ciencias Exactas, Físico-Químicas y Naturales. Universidad Nacional de Río Cuarto. Río Cuarto, Argentina.

* Correo electrónico del autor de contacto:fmanas@ayv.unrc.edu.ar

\begin{abstract}
Resumen
El objetivo del trabajo fue evaluar in vitro algunos potenciales efectos terapéuticos del extracto etanólico de romero (Rosmarinus officinalis L.), incluyendo sus actividades inhibitoria sobre la formación de biopelícula, antimicrobiana, antioxidante y protectora del ADN. La evaluación de la actividad antimicrobiana se llevó a cabo mediante la técnica de difusión en pocillo y determinaciones de concentración inhibitoria mínima (CIM) y concentración bactericida mínima (CBM), empleando dos bacterias gram (+) y tres gram (-). La determinación de la actividad inhibitoria sobre la formación de biopelícula se realizó con el microorganismo que presentó mayor sensibilidad a la actividad antimicrobiana del romero, empleando una técnica en placa de 96 pocillos. La cuantificación de las actividades antioxidante y antigenotóxica se llevó a cabo sobre leucocitos caprinos, expuestos al extracto y a $\mathrm{H}_{2} \mathrm{O}_{2}$, mediante cuantificación de lipoperoxidación y daño en el ADN (ensayo cometa), respectivamente. Los resultados obtenidos indican mayor sensibilidad de los microorganismos gram (+) al extracto de romero (CIM/CBM 312,5/1250 y 312,5/2500 $\mu \mathrm{g} / \mathrm{ml}$ para $S$. aureus y $S$. epidermidis, respectivamente), en tanto no se halló sensibilidad en los gram (-). Se encontró actividad inhibitoria sobre la formación de biopelícula aun a concentraciones subinhibitorias para $S$. aureus en placa de 96 pocillos. Finalmente, se demostró que el extracto de romero presenta actividad protectora del ADN en células caprinas que podría estar vinculada con un efecto antioxidante. Resulta necesario continuar investigando la capacidad antimicrobiana del extracto de romero para evaluar la posibilidad de emplearlo in vivo para el tratamiento de infecciones crónicas relacionadas con la presencia de biopelícula.
\end{abstract}

\section{Palabras clave}

Romero, antibiopelícula, antioxidante, antigenotóxico

\begin{abstract}
The aim of the present work was to evaluate the antimicrobial, antibiofilm, antioxidant and DNA protective activities of a rosemary (Rosmarinus officinalis L.) ethanolic extract. The antimicrobial activity evaluation was carried out by the well diffusion method, and determinations of minimum inhibitory concentration (MIC) and minimum bactericidal concentration (MBC) in 96-well plates using two gram (+) and three gram (-) bacteria. Determination of the inhibitory activity on biofilm formation was carried out with the microorganism which showed the highest sensitivity to the antimicrobial activity of rosemary, using a 96-well plate technique. Quantification of antioxidant and antigenotoxic activities was carried out on goat leukocytes exposed to the extract and to $\mathrm{H}_{2} \mathrm{O}_{2}$, by quantifying lipoperoxidation and DNA damage (comet assay), respectively. Results obtained indicate that there could be a greater sensitivity of the gram $(+)$ microorganisms to the rosemary extract (MIC/MBC $312.5 / 1250$ and $312.5 / 2500 \mu \mathrm{g} / \mathrm{ml}$ for $S$. aureus and $S$. epidermidis, respectively), while no sensitivity was evidenced in the gram (-) bacteria evaluated. An inhibitory activity on biofilm formation for S. aureus in 96-well plate, even at subinhibitory concentrations, was found. Finally, it was demonstrated that the extract of rosemary presents a DNA protective activity in goat cells, which could be linked to an antioxidant effect. Further research on the antimicrobial capacity of rosemary extract is required in order to evaluate the possibility of using it in vivo for the treatment of chronic infections related to the presence of biofilm.
\end{abstract}

\section{Key words}

Rosemary, antibiofilm, antioxidant, antigenotoxic

Fecha de recepción: 07/03/2018

ANALECTA VeT 2018; Julio-Diciembre; 38(2):1-9

Impresa ISSN 03655 14-8 Electrónica ISSN 1514-2590

Fecha de aprobación: 03/07/2018

doi.org/10.24215/15142590eo26 


\section{Introducción}

Una de las actividades biológicas que se les atribuyen a diversas especies vegetales es la capacidad de actuar sobre la biopelícula, inhibiendo su formación o erradicándola. El término biopelícula fue utilizado por primera vez en 1978 para hacer referencia a una comunidad organizada de bacterias, algas, hongos, protozoarios, protegidos por una matriz formada por una mezcla de compuestos poliméricos, principalmente polisacáridos. Más del $99 \%$ de los microorganismos de la Tierra viven en estas condiciones (Vu et al., 2009), protegidos así de diversas condiciones ambientales adversas, incluyendo el contacto con los antimicrobianos tradicionales. Hasta la fecha, se ha hallado gran cantidad de extractos vegetales y fitoterápicos con capacidad de actuar sobre la biopelícula (Borges et al., 2016; Sasirekha et al., 2015).

Otra importante actividad terapéutica de muchas plantas medicinales se relaciona con su capacidad antioxidante. El estrés oxidativo ha sido asociado con el desarrollo de muchos procesos patológicos en animales, incluyendo enfermedades infecciosas como neumonías, enteritis y sepsis, mastitis, laminitis, enfermedades articulares en general, endotoxemia, endometritis, obstrucciones de las vías aéreas y diversas condiciones relacionadas con el ejercicio (Lykkesfeldt \& Svendsen, 2007), por lo que el uso de plantas ricas en antioxidantes se presenta como un objetivo para explorar en el futuro en el ámbito de la nutrición animal (Celi \& Gabai, 2015).

Una de las plantas que ha recibido atención en los últimos años, en cuanto a su capacidad antibacteriana, antibiopelícula y antioxidante, es el romero (Rosmarinus officinalis L.) (Ceylan et al., 2014). Si bien las propiedades biológicas del romero han sido estudiadas, su potencial actividad terapéutica no ha sido completamente caracterizada (Issabeagloo et al., 2012). Se ha reportado que tanto el extracto o su aceite esencial, así como algunos de sus constituyentes, podrían tener actividad antimicrobiana (Ulbricht et al., 2010). Por otro lado, si bien ha sido estudiada la actividad antioxidante del romero (Afonso et al., 2013), existe poca información disponible sobre los posibles efectos que esta actividad antioxidante podría tener sobre el material genético.

La validación de propiedades terapéuticas y evaluación toxicológica de plantas medicinales es sumamente importante debido a que el desarrollo de nuevos medicamentos desde principios activos de origen vegetal complementará el arsenal cada vez menor de antimicrobianos y antiparasitarios actualmente disponible (Toyang et al., 2012), y a que los polifenoles presentes en muchas de ellas tendrían una gran capacidad antioxidante y antigenotóxica (Genena et al., 2008). El objetivo del presente estudio fue evaluar, en modelos in vitro, algunos de los potenciales efectos terapéuticos del extracto de romero, incluyendo su actividad inhibitoria sobre la formación de biopelícula y sus actividades antimicrobiana, antioxidante $\mathrm{y}$ protectora del ADN.

\section{Materiales y métodos}

\section{Material vegetal}

Las hojas de romero fueron recolectadas en la localidad de Alpa Corral, Departamento de Río Cuarto, Provincia de Córdoba $\left(32^{\circ} 41^{\prime} 24^{\prime \prime S}\right.$ $64^{\circ} 43^{\prime} 16^{\prime \prime} \mathrm{O}$ ), durante el mes de octubre de 2015. La recolección se realizó en horas de la mañana, y las hojas fueron conservadas y posteriormente secadas a temperatura ambiente durante cinco días en hojas de papel absorbente. Una vez transcurrido el período de secado, las hojas se molieron manualmente, y el material molido se almacenó a $5{ }^{\circ} \mathrm{C}$ y al abrigo de la luz.

\section{Preparación del extracto etanólico}

Cinco gramos de hojas molidas de romero se sometieron a extracción con $100 \mathrm{ml}$ de etanol de $96^{\circ}$ al $80 \%$ durante cinco días, al abrigo de la luz y con agitación periódica. Al cabo de esos cinco días se filtró con papel Whatman $\mathrm{N}^{\circ} 1$. Este extracto se concentró en evaporador rotatorio a $70{ }^{\circ} \mathrm{C}$ hasta sequedad y el residuo sólido se disolvió en DMSO o etanol absoluto a una concentración de $200 \mathrm{mg} /$ $\mathrm{ml}$. Las diluciones de trabajo fueron realizadas en solución de DMSO al $5 \%$ en agua para los ensayos microbiológicos (difusión en agar, CIM, CBM, e inhibición en la formación de biopelícula) o en etanol absoluto para los ensayos toxicológicos (TBARs, azul de tripán y ensayo cometa).

\section{Evaluación de la actividad antimicrobiana}

Las cepas utilizadas para evaluar la actividad antimicrobiana del extracto etanólico de Rosmarinus officinalis L. fueron: Escherichia coli, Staphylococcus aureus, Staphylococcus epidermidis y Pseudomonas aeruginosa (cedidas por el Departamento de Microbiología de la Facultad de Ciencias Exactas Físico-Químicas y Naturales) y Escherichia coli (FV 10188), provista por el Departamento de Anatomía de la Facultad de Agronomía y Veterinaria, ambos departamentos pertenecientes a la Universidad Nacional de Río Cuarto.

\section{Ensayo de difusión en agar}

La actividad antibacteriana del extracto de romero se evaluó empleando la técnica de difusión en agar. Las cepas fueron incubadas en caldo cerebro corazón durante $18 \mathrm{~h}$ a $37^{\circ} \mathrm{C}$; estos cultivos fueron luego ajustados a una densidad de 108 UFC/ 
ml según la escala de McFarland. Posterior-mente, se sembraron $100 \mu \mathrm{l}$ de cada cultivo en placas de Petri con agar Mueller-Hinton (AMH) distribuyéndolo uniformemente con espátula de Drigalsky. En cada placa se realizaron tres pocillos de $6 \mathrm{~mm}$ de diámetro perforando el agar con un sacabocado estéril. En uno de los pocillos se colocaron $50 \mu \mathrm{l}$ del extracto de romero disuelto en DMSO a una concentración de $10 \mathrm{mg} / \mathrm{ml}$, en otro pocillo se colocó idéntico volumen de DMSO como control del vehículo y el último se tomó como control positivo, empleando una solución de ciprofloxacina (Recalcine Laboratories, Chile) de grado HPLC con un $87 \%$ de pureza, a una concentración de $200 \mu \mathrm{g} / \mathrm{ml}$. Finalmente, las placas se incubaron a $37^{\circ} \mathrm{C}$ durante 24 horas. Las pruebas se realizaron por duplicado para cada cepa. La interpretación de los halos y la clasificación de los microorganismos se llevó a cabo siguiendo las directivas del Clinical and Laboratory Standards Institute (CLSI, 2012). Para el caso del extracto de romero y el DMSO (control de vehículo), se registraron los diámetros de los halos de inhibición con la finalidad de determinar presencia o ausencia de actividad inhibitoria. Esta fue luego cuantificada mediante la determinación de concentraciones inhibitoria y bactericida mínima.

\section{Determinación de la CIM (concentración inhibitoria mínima) y la CBM (concentración bactericida mínima)}

La cuantificación de concentraciones mínimas inhibitorias y bactericidas se llevó a cabo para ciprofloxacina y extracto de romero, empleando las cinco cepas en estudio. Para la determinación de la CIM se llevó a cabo el método de microdilución en placa de 96 pocillos descripto por el CLSI (2012). Se colocaron $100 \mu \mathrm{l}$ de caldo Müeller-Hilton (CMH) en todos los pocillos, exceptuando las tres últimas columnas que fueron reservadas para los controles. En los pocillos de la primera columna se agregaron $10 \mu \mathrm{l}$ del extracto disuelto en DMSO, logrando una concentración de $10 \mathrm{mg} / \mathrm{ml}$, a partir de la cual se realizaron ocho diluciones seriadas para obtener las concentraciones a evaluar (10 000; 5000; 2500; 1250; 620; $310 ; 150 ; 80$ y $40 \mu \mathrm{g} / \mathrm{ml})$. Por último, se completó cada pocillo con $90 \mu \mathrm{l}$ de la suspensión del microorganismo (108 UFC/ml según la escala de McFarland) y, en todos los casos, el DMSO quedó a una concentración final del $5 \%$. En la columna de control de vehículo, se colocaron $100 \mu \mathrm{l}$ de $\mathrm{CMH}$, 90 $\mu \mathrm{l}$ del inóculo y $10 \mu \mathrm{l}$ de DMSO. La columna de control negativo se completó con $\mathrm{CMH}$ $(190 \mu \mathrm{l})$ y DMSO $(10 \mu \mathrm{l})$ como control de esterilidad. La columna de control positivo fue completada con $100 \mu \mathrm{l}$ de $\mathrm{CMH}$ y $100 \mu \mathrm{l}$ de inóculo. Las placas se incubaron a $37^{\circ} \mathrm{C}$ durante 18 horas.

La CIM para ciprofloxacina se llevó a cabo del mismo modo. En este caso, el antimicrobiano fue disuelto en el mismo caldo Müeller-Hilton y se evaluaron las siguientes concentraciones: 98,00; 49,$00 ; 24,50 ; 12,25 ; 6,12 ; 3,06 ; 1,53 ; 0,76$ у 0,38 $\mu \mathrm{g} / \mathrm{ml}$. Se incluyeron un control de esterilidad (control negativo consistente en $200 \mu \mathrm{l}$ de $\mathrm{CMH}$ ) y un control positivo (100 $\mu \mathrm{l}$ de CMH y $100 \mu \mathrm{l}$ de la suspensión del microorganismo).

En todos los casos, la CIM se determinó como la mínima concentración del compuesto evaluado que inhibe completamente el crecimiento bacteriano y se expresó en $\mu \mathrm{g} / \mathrm{ml}$. Para la determinación de la CBM, se tomaron $100 \mu$ l de cada uno de los tratamientos que no presentaron turbidez luego de la incubación, así como también de los controles, y se los inoculó sobre una placa con $\mathrm{AMH}$, diseminando con espátula de Drigalsky. La CBM se calculó como la mínima concentración del compuesto que no permite el crecimiento visible de colonias en la placa de Petri.

\section{Inhibición de la formación de biopelícula}

La cuantificación de la formación de biopelícula en superficie abiótica fue determinada según el método descrito por Dubravka et al. (2010), con algunas modificaciones, para el microoganismo más sensible al extracto de romero según el método de microdilución en placas de 96 pocillos. Para la preparación del inóculo, el microorganismo fue multiplicado en caldo tripticasasoya (CTS) durante $24 \mathrm{~h}$, a $37^{\circ} \mathrm{C}$. Se tomaron alícuotas de $100 \mu \mathrm{l}$ de la suspensión del microorganismo (108 UFC/ml según la escala de McFarland) y se inocularon en pocillos de placas de poliestireno de 96 pocillos. Se adicionaron cinco concentraciones del extracto de romero disueltas en DMSO (312,50; 156,25; 78,12; 39,06 y $19,53 \mu \mathrm{g} / \mathrm{ml}$ ), y se incluyeron controles negativos (CTS y DMSO sin inóculo) y controles positivos (CTS y DMSO con inóculo). Todos los pocillos recibieron idénticas proporciones de DMSO y CTS. Las placas fueron incubadas a $37^{\circ} \mathrm{C}$ durante $24 \mathrm{~h}$, tras lo cual se procedió a remover el contenido y enjuagar los pocillos tres veces con agua destilada estéril. Finalmente se adicionaron a cada pocillo $200 \mu \mathrm{l}$ de metanol como fijador, y se realizó la tinción con $160 \mu \mathrm{l}$ de una solución al $0,5 \%$ de cristal violeta. La decoloración se llevó a cabo con una solución de ácido tricloroacético al 30 \%, cuya densidad óptica (DO) se midió a $492 \mathrm{~nm}$ en un espectrofotómetro. Estas determinaciones fueron realizadas por triplicado.

\section{Evaluación del balance oxidativo y efectos sobre el ADN}

\section{Tratamiento de las muestras}

Se obtuvieron muestras de sangre $(16 \mathrm{ml}$ en jeringa heparinizada) de tres caprinos machos, adultos y clínicamente sanos. Cada muestra de sangre entera se dividió en 8 tubos y se incubó a $37^{\circ} \mathrm{C}$ en movimiento constante mediante agitador orbital con cinco concentraciones del extracto de 
romero disuelto en etanol absoluto $(312,5 ; 156,2$; 78,$1 ; 39,1$ y $19,5 \mu \mathrm{g} / \mathrm{ml}$ ), un control negativo (sangre con etanol) y un control positivo (sangre que luego fue expuesta únicamente a $\mathrm{H}_{2} \mathrm{O}_{2} 30 \mu \mathrm{M}$ ) durante 15 minutos. Transcurrido este período se adicionó $\mathrm{H}_{2} \mathrm{O}_{2}(30 \mu \mathrm{M})$ a todos los tubos (excepto al control negativo) y volvió a incubarse a $37^{\circ} \mathrm{C}$ durante 30 minutos. Tras el tratamiento de las muestras, estas se fraccionaron en dos tubos $(1 \mathrm{ml}$ cada uno), a los que se les realizó la cuantificación de los niveles de lipoperoxidación mediante el ensayo de sustancias reactivas al ácido tiobarbitúrico (TBARs) y del daño en el ADN mediante el ensayo cometa. Este diseño se repitió en tres oportunidades diferentes, tomando las muestras de sangre a los tres animales, durante tres semanas consecutivas.

\section{Determinación de sustancias reactivas al ácido tiobarbitúrico (TBARs)}

La cuantificación de sustancias reactivas al ácido tiobarbitúrico (TBARs) se llevó a cabo en el plasma de las muestras de sangre tratadas, según el método descripto por Buege \& Aust (1978), modificado por Marcincak et al. (2003), utilizando malondialdehído (MDA) como sustancia de referencia. Se utilizó una curva de calibración de concentraciones conocidas de MDA $(1,3 ; 2,9 ; 4,3$; 6,$5 ; 9,7 ; 14,6$ y $29,3 \mathrm{nmol}$ de $\mathrm{MDA} / \mathrm{ml}$ ), obtenido mediante hidrólisis del 1,1,3,3-tetrametoxipropano. Cada muestra fue analizada por triplicado en las tres muestras de sangre tomadas a cada uno de los tres animales, obteniéndose un total de 27 datos (nueve para cada animal). Los resultados se expresaron como $\mathrm{nmol}$ de $\mathrm{MDA} / \mathrm{ml}$ de plasma.

\section{Aislamiento de leucocitos de sangre periférica caprina}

Se aislaron los leucocitos del paquete globular mediante lisis de los eritrocitos. Una vez separado el plasma, se resuspendió el paquete globular en una solución tamponada de lisis $(8,3 \mathrm{~g} / \mathrm{l}$ de $\mathrm{NH}_{4} \mathrm{Cl} ; 0,5 \mathrm{~g} / \mathrm{l} \mathrm{KHCO} 3$ y 18,5 mg/l de EDTA). Se dejaron reposar los tubos a $4{ }^{\circ} \mathrm{C}$ durante 10 minutos y se centrifugó nuevamente, repitiendo el procedimiento dos veces, para finalmente resuspender los glóbulos blancos obtenidos en PBS (Brendler-Schwaab et al., 1994).

\section{Viabilidad y recuento celular mediante la tinción con azul tripán}

Se evaluó la viabilidad celular mediante la tinción con azul tripán (Freshney, 2000). El recuento celular fue realizado por dos observadores y se llevó la suspensión hasta una concentración de $3 \times 10^{6}$ células/ml para realizar el ensayo cometa.

\section{Ensayo cometa}

El ensayo fue realizado siguiendo el protocolo descripto por Singh et al. (1988) con algunas modificaciones. Se mezclaron $250 \mu \mathrm{l}$ de agarosa de bajo punto de fusión (ABPF) (Promega) con $50 \mu \mathrm{l}$ de la suspensión de leucocitos. De esa mezcla, se colocaron $65 \mu \mathrm{l}$ en un portaobjetos previamente tratado con $200 \mu \mathrm{l}$ de agarosa de punto de fusión normal (APFN). Finalmente, se adicionó una tercera capa de ABPF y se depositaron los portaobjetos en recipientes con solución de lisis $(\mathrm{NaCl} 2,5 \mathrm{M}$, EDTA $100 \mathrm{mM}$ y Tris $10 \mathrm{mM}, 10 \%$ de dimetilsulfóxido y $1 \%$ de tritón) a $4{ }^{\circ} \mathrm{C}$ durante una hora. A continuación, se llevó a cabo la corrida electroforética durante treinta minutos a $30 \mathrm{~V} \mathrm{y}$ $250 \mathrm{~mA}$ utilizando una solución alcalina $(\mathrm{pH} \geq 11)$. Los portaobjetos fueron neutralizados mediante el goteo de una solución de neutralización (Tris 0,4 M) a $\mathrm{pH}$ 7,5. Por último, se colorearon los portaobjetos con bromuro de etidio y de inmediato se analizaron en el microscopio de fluorescencia. Se tomaron fotografías de, al menos, 100 nucleoides que fueron analizados mediante el programa Comet Score 1.5® Tri Tek Co. El parámetro elegido para evaluar el daño en el ADN fue el momento de la cola. Los cometas sin núcleo detectable o "nubes" no fueron considerados en el análisis.

\section{Análisis estadístico}

Se realizó un análisis de la varianza (ANOVA) para evaluar las diferencias entre los distintos tratamientos y se realizaron a posteriori las pruebas de Tukey y Dunn. El supuesto de normalidad fue corroborado mediante la prueba de Kolmogorov-Smirnov. Se utilizó el coeficiente de Pearson para determinar la relación existente entre la concentración de romero y los parámetros de cada uno de los ensayos utilizados (relación dosis-respuesta), y para evaluar una posible relación entre el daño en el ADN y la lipoperoxidación por especies reactivas del oxígeno.

\section{Resultados}

\section{Actividad antimicrobiana}

Los resultados obtenidos mediante el ensayo de difusión en agar indican la existencia de actividad antimicrobiana del extracto de romero frente a $S$. aureus y $S$. epidermidis, obteniéndose halos de inhibición de 9 y $10 \mathrm{~mm}$, respectivamente. No se observaron halos de inhibición para ninguna de las tres bacterias gram negativas evaluadas. Del mismo modo, no se visualizaron halos de inhibición en ninguna de las bacterias expuestas a DMSO como control de vehículo. El antimicrobiano ciprofloxacina produjo un efecto inhibitorio sobre las cinco bacterias evaluadas, obteniéndose halos de inhibición con los siguien- 
tes diámetros: S. aureus, $10 \mathrm{~mm}$; S. epidermidis, $12 \mathrm{~mm}$; P. aeruginosa, $21 \mathrm{~mm} ; E$. coli, $40 \mathrm{~mm} ; E$. coli (FV 10188), $36 \mathrm{~mm}$.

Fue posible obtener valores de CIM y CBM del extracto de romero únicamente para las bacterias gram positivas. Se observó una CIM de 312,5 y una CBM de $1250 \mu \mathrm{g} / \mathrm{ml}$ para el $S$. aureus, mientras que para el $S$. epidermidis los valores fueron de 312,5 y $2500 \mu \mathrm{g} / \mathrm{ml}$ para la CIM y CBM, respectivamente. La ciprofloxacina no inhibió el crecimiento de $S$. aureus en las concentraciones ensayadas, por lo que no se obtuvieron valores de CIM y CBM para este microorganismo. Para el $S$. epidermidis, se obtuvieron valores de 3,1 y 12,5 $\mathrm{\mu g}$ / ml para CIM y CBM, respectivamente. En cuanto a las bacterias gram negativas, $P$. aeruginosa fue la que exhibió el valor de CIM más bajo, de 1,6 $\mu \mathrm{g} /$ $\mathrm{ml}$; en tanto la CBM llegó a $50 \mu \mathrm{g} / \mathrm{ml}$. Para las bacterias $E$. coli analizadas, los valores fueron idénticos en ambos casos, obteniéndose valores de CIM de 6,2 $\mu \mathrm{g} / \mathrm{ml}$ y CBM de $12,5 \mu \mathrm{g} / \mathrm{ml}$ (Tabla 1 ).

\begin{tabular}{lcc}
\hline \multirow{2}{*}{ Microorganismo } & \multicolumn{2}{c}{ Antimicrobiano } \\
\cline { 2 - 3 } & $\begin{array}{c}\text { Ciprofloxacina } \\
\text { CIM/CBM }(\mu \mathrm{g} / \mathrm{ml})\end{array}$ & $\begin{array}{c}\text { Extracto de romero } \\
\text { CIM/CBM }(\mu \mathrm{g} / \mathrm{ml})\end{array}$ \\
\hline E. coli & $6,2 / 12,5$ & $\mathrm{NI}$ \\
E. coli $(F V$ 10188) & $6,2 / 12,5$ & $\mathrm{NI}$ \\
P. aeruginosa & $1,6 / 50$ & $\mathrm{NI}$ \\
S. aureus & $\mathrm{NI}$ & $312,5 / 1250$ \\
S. epidermidis & $3,1 / 12,5$ & $312,5 / 2500$ \\
\hline
\end{tabular}

NI: No inhibió.

Tabla 1. Método de dilución en caldo en placa de 96 pocillos.

De acuerdo con los resultados de CIM y CBM del extracto de romero para los distintos microorganismos analizados, se procedió a seleccionar a $S$. aureus para evaluar la capacidad del extracto de romero de inhibir la formación de biopelícula en placa de 96 pocillos.

La figura 1 muestra una disminución estadísticamente significativa de la formación de biopelícula en cultivos de $S$. aureus tratados con 78,12 (p so,o1; prueba de Tukey); 156,25 y 312,5 $\mu \mathrm{g} / \mathrm{ml}$ ( $\mathrm{p} \leq \mathrm{0}, 001$; prueba de Tukey) del extracto de romero en placas de 96 pocillos durante $24 \mathrm{~h}$. También se observó una diferencia estadísticamente significativa entre el control negativo (sin inóculo) y los pocillos tratados con DMSO (p $\leq 0,001$; prueba de Tukey), lo que demuestra que el DMSO en la concentración empleada no inhibe la formación de biopelícula en superficies abióticas.

En la figura 2 se observa una disminución dosis-respuesta (R: -0,9112, prueba de Pearson, $p$ $\leq 0,05$ ) en la formación de biopelícula por $S$. aureus expuesto a distintas concentraciones del extracto etanólico de romero disuelto en DMSO.

\section{Actividad antioxidante}

En la tabla 2 se muestran los resultados correspondientes a la cuantificación en los niveles de lipoperoxidación en plasma de sangre caprina tratada simultáneamente con $\mathrm{H}_{2} \mathrm{O}_{2}$ y extracto de romero. No fue posible obtener resultados para la concentración más elevada $(312,5 \mu \mathrm{g} / \mathrm{ml})$ del extracto de romero debido a interferencias en la lectura espectrofotométrica de las muestras provocadas por la generación de hemólisis durante la incubación. Se obtuvieron un total de 9 datos por cada concentración ensayada.

\begin{tabular}{|c|c|c|c|c|c|c|c|c|c|c|}
\hline \multirow{2}{*}{$\begin{array}{l}\begin{array}{l}\text { Extracto } \\
\text { de } \\
\text { romero } \\
(\mu \mathrm{g} / \mathrm{ml})\end{array} \\
156,25\end{array}$} & \multicolumn{9}{|c|}{ Nmoles de MDA por ml de plasma } & \multirow{2}{*}{$\begin{array}{l}\text { Media } \pm \mathrm{DF} \\
2,36 \pm 1,02\end{array}$} \\
\hline & 2,21 & 1,61 & 2,16 & 3,32 & 0,93 & 1,21 & 3,90 & 3,35 & 2,63 & \\
\hline 78,25 & 0,87 & 1,33 & 3,56 & 4,94 & 3,40 & 2,02 & 3,94 & 2,17 & 3,27 & $2,83 \pm 1,31$ \\
\hline 39,06 & 1,63 & 2,83 & 2,10 & 2,95 & 1,57 & 2,69 & 4,26 & 7,83 & 1,80 & $3,07 \pm 1,97$ \\
\hline 19,53 & 1,26 & 1,89 & 3,38 & 2,22 & 2,82 & 1,83 & 2,46 & 5,93 & 5,29 & $3,00 \pm 1,60$ \\
\hline 0,00 & 2,84 & 0,45 & 3,85 & 2,92 & 2,83 & 1,15 & 5,740 & 6,29 & 2,830 & $3,21 \pm 1,89$ \\
\hline
\end{tabular}

Tabla 2. Niveles de malondialdehído (MDA) por ml de plasma en sangre caprina tratada con $\mathrm{H}_{2} \mathrm{O}_{2}$ y cuatro concentraciones de extracto de romero disuelto en etanol.

Si bien no se obtuvieron diferencias estadísticamente significativas entre los distintos tratamientos, en la figura 3 puede observarse una correlación negativa entre los niveles de $\mathrm{MDA} / \mathrm{ml}$ de plasma y las concentraciones crecientes de extracto de romero (R: -0,9812, $\mathrm{p} \leq 0,01$; prueba de Pearson).

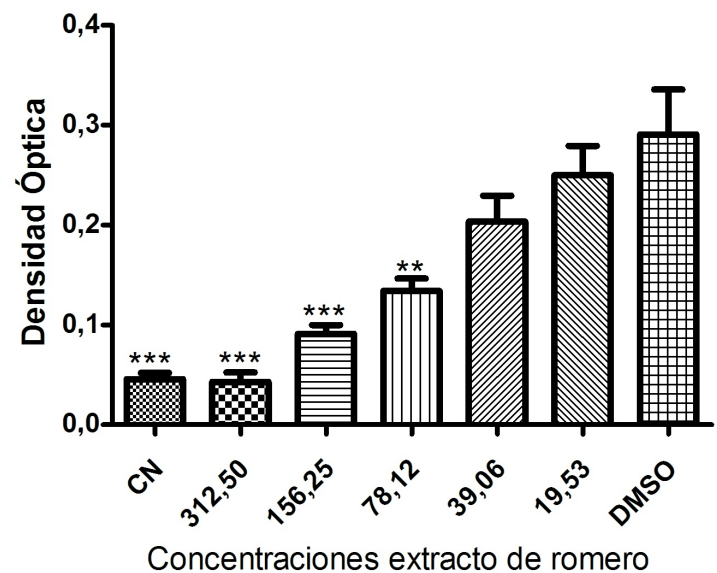

Figura 1. Cuantificación en la formación de biopelícula por $S$. aureus expuesto a distintas concentraciones de extracto de romero en placa de 96 pocillos. Concentraciones expresadas en $\mu \mathrm{g} / \mathrm{ml}$. CN: control negativo. DMSO como control de vehículo. ${ }^{* * *} \mathrm{p} \leq 0,001 ;{ }^{* *} \mathrm{p} \leq 0,01 ;$ prueba de Tukey.

\section{Viabilidad celular}

Los resultados del ensayo de azul tripán arrojaron una viabilidad superior al $90 \%$ en todos los casos. 


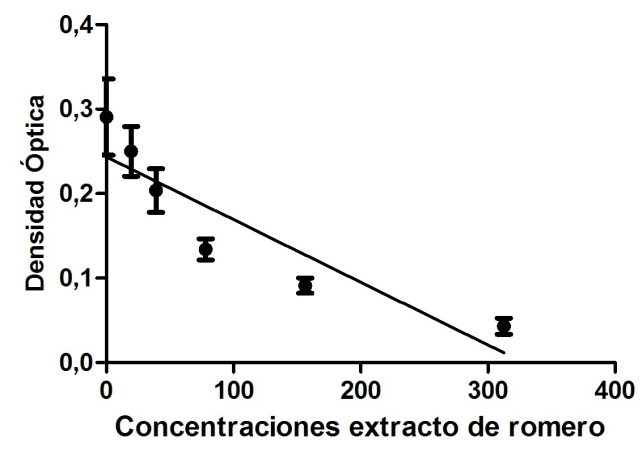

Figura 2. Correlación entre niveles de formación de biopelícula (D.O.) y concentraciones de extracto de romero en cultivos de $S$. aureus en placas de 96 pocillos. R: -0,9112, prueba de Pearson, $\mathrm{p} \leq \mathrm{0}, 05$.

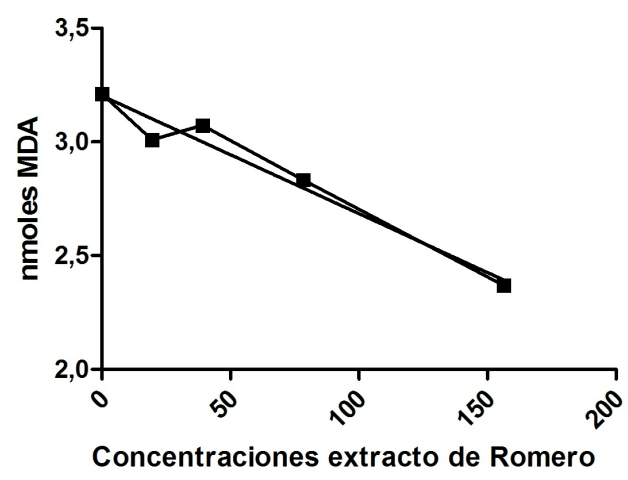

Figura 3. Nmoles de Malondialdehído (MDA) versus concentraciones de extracto de romero en sangre caprina expuesta a $\mathrm{H}_{2} \mathrm{O}_{2}(30 \mu \mathrm{M})$. Concentraciones expresadas en $\mu \mathrm{g} / \mathrm{ml}$. CN: control negativo. Etanol como control de vehículo.

\section{Actividad protectora del ADN}

Con respecto al efecto del extracto de romero sobre la integridad del ADN evaluado mediante el ensayo cometa, se encontró una disminución estadísticamente significativa en los niveles de daño en leucocitos expuestos a $\mathrm{H}_{2} \mathrm{O}_{2}$ y tratados con 156,25 y $312,5 \mu \mathrm{g} / \mathrm{ml}$ de extracto de romero ( $\mathrm{p} \leq 0,05$ y 0,001 , respectivamente; prueba de Dunn), con respecto a aquellas células expuestas únicamente a $\mathrm{H}_{2} \mathrm{O}_{2}$ (Figura 4).

Se observó una disminución dosis-respuesta en los niveles de daño en el ADN en leucocitos expuestos a $\mathrm{H}_{2} \mathrm{O}_{2}$ y tratados con distintas concentraciones del extracto de romero (R:

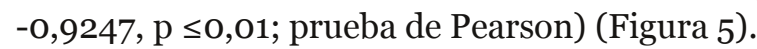

\section{Discusión y conclusiones}

Los resultados obtenidos en el presente trabajo sugieren que el extracto etanólico de romero posee actividad antimicrobiana frente a $S$. aureus y $S$. epidermidis. Estos datos concuerdan con los publicados en la bibliografía disponible, que sugieren que $S$. aureus es uno de los microorganismos más sensibles a los efectos antimicrobianos de los extractos de romero (Klancnik et al., 2009; Santoyo et al., 2005). Balouiri et al., (2014) reportan, del mismo modo, una actividad remarcable de romero contra bacterias gram $(+)$ (Bacillus subtilis y $S$. aureus), pero una notable resistencia al mismo extracto por parte de bacterias gram (-) (Balouiri et al., 2014). S. aureus es uno de los agentes productores de mastitis de mayor prevalencia, y se cree que aquellas cepas de $S$. aureus con habilidad de producir biopelícula tendrían una mayor capaci-dad de colonizar las glándulas mamarias que aquellas variantes no productoras de biopelícula (Dubravka et al., 2010). En este sentido, la adhesión a las superficies mucosas sería un paso determinante en el establecimiento de las infecciones persistentes y/ o crónicas (Fox et al., 2005).

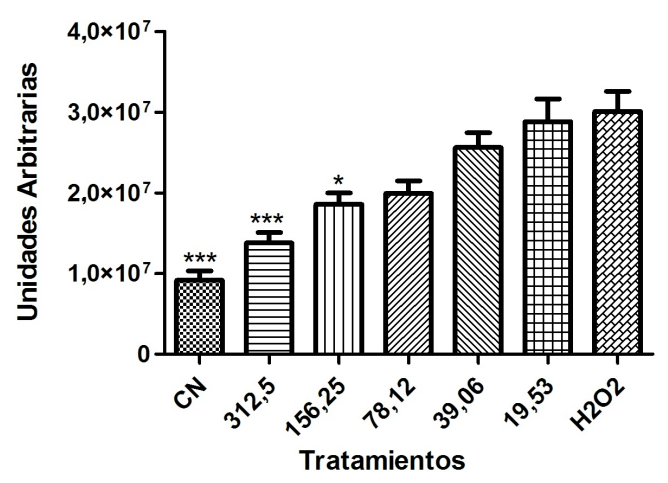

Figura 4. Magnitud del daño en el ADN en leucocitos expuestos a $\mathrm{H}_{2} \mathrm{O}_{2}$ y tratados con distintas concentraciones de extracto de romero. ${ }^{*} \mathrm{p} \leq 0,05 .{ }^{* * *} \mathrm{p} \leq 0,001$. Concentraciones expresadas en $\mu \mathrm{g} / \mathrm{ml}$.

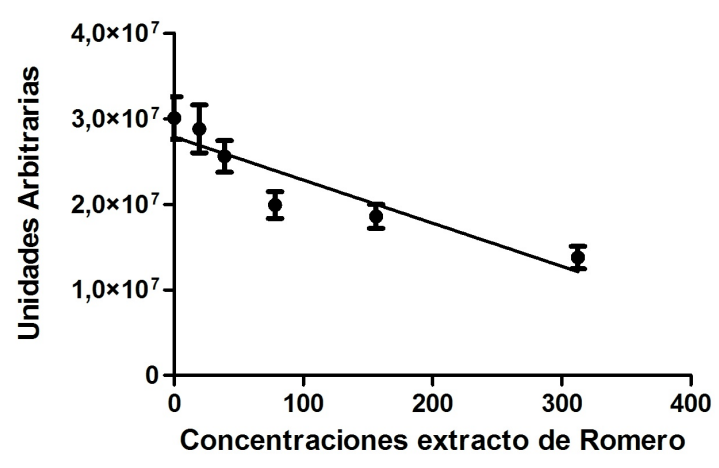

Figura 5. Correlación entre el daño en el ADN en leucocitos expuestos a $\mathrm{H}_{2} \mathrm{O}_{2}$ y distintas concentraciones de extracto de romero. R: $0,9247, \mathrm{p} \leq \mathrm{0}, 01$; prueba de Pearson.

Estudios in vitro sugieren que el efecto antimicrobiano del romero podría ser atribuido, al menos en parte, a su habilidad para prevenir la adhesión celular o la producción de biopelícula. El aceite de romero exhibe una potente capacidad de 
inhibir la percepción de cuórum (quorum sensing), lo cual reduciría la patogenicidad y la resistencia a los antimicrobianos (Ulbricht et al., 2010). En el presente estudio, fue posible demostrar que el extracto etanólico de romero produce una disminución concentración dependiente, en la formación de biopelícula por parte de $S$. aureus en placas de 96 pocillos. Se halló también una diferencia estadísticamente significativa entre el control negativo y los pocillos tratados con DMSO como control de vehículo. Esto demuestra que el DMSO, en la concentración empleada, no tiene efecto sobre la producción de biopelícula y no sería, por lo tanto, el responsable de los efectos hallados. Un aspecto que refuerza la evidencia del efecto inhibitorio del extracto de romero sobre la producción de biopelícula es que tal efecto tiene un comportamiento concentración-efecto demostrando, por tanto, que a mayores concentraciones del extracto la inhibición sobre la producción de biopelícula es mayor. Por último, es importante resaltar que el efecto inhibidor sobre la formación de biopelícula se consigue aun con concentraciones subinhibitorias $(78,12$ y $156,25 \mu \mathrm{g} / \mathrm{ml})$, con las que no se observó ningún efecto sobre el crecimiento planctónico de $S$. aureus.

Se ha investigado también la actividad antioxidante de hojas y extractos de romero, e incluso debido a su contenido en sustancias antioxidantes se los utiliza para reemplazar antioxidantes sintéticos como butilhidroxianisol y butilhidroxitolueno (Martín Zurro, 2004). Algunos de los constituyentes activos del romero son el ácido cafeico, el ácido rosmarínico, el carnosol y el ácido carnósico, todos ellos con aparente actividad antioxidante (Ulbricht et al., 2010). Existe evidencia de que los compuestos antioxidantes del romero, incluyendo polifenoles y flavonas, están presentes en extractos hidroalcohólicos (AvilaSosa et al., 2011). La actividad antioxidante de los compuestos presentes en la planta y los extractos de romero es atribuida a su habilidad de actuar como agentes reductores y "atrapadores" de radicales libres, así como a la capacidad de formar complejos iones metálicos prooxidantes (Aherne et al., 2007). Ensayos en ratas sugieren que los compuestos fenólicos encontrados en el romero protegen contra el estrés oxidativo, incrementando la actividad de enzimas antioxidantes y reduciendo la oxidación lipídica (Afonso et al., 2013).

En el presente trabajo se halló una correlación negativa, estadísticamente significativa, entre las concentraciones de romero ensayadas y los niveles de lipoperoxidación cuantificados mediante el ensayo de TBARs. Si bien las diferencias entre los distintos tratamientos no fueron estadísticamente significativas, la relación hallada entre el incremento de concentraciones de extracto de romero y la disminución en los niveles de oxidación lipídica sugiere que este extracto podría tener algún efecto protector sobre las células, evitando por ejemplo el daño oxidativo sobre el ADN.
En ese sentido, y empleando una técnica de gran sensibilidad como el ensayo cometa, fue posible poner en evidencia un efecto protector del extracto de romero sobre el ADN de leucocitos expuestos a $\mathrm{H}_{2} \mathrm{O}_{2}$. Del mismo modo, otros autores reportan un efecto antigenotóxico del extracto de romero en cultivos celulares expuestos a peróxido de hidrógeno. En este caso, el efecto protector sobre el ADN fue logrado con concentraciones menores $(15 \mu \mathrm{g} / \mathrm{ml})$ a las determinadas como antigenotóxicas en el presente estudio (Aherne et al., 2007). Esta diferencia podría explicarse debido que el tiempo de exposición al extracto de romero empleado por estos autores fue de 24 horas, en tanto que en nuestro caso el tiempo de exposición previo fue de tan solo 15 minutos. Otros autores sugieren que el efecto protector del extracto de romero sobre el ADN podría deberse a su efecto antioxidante o a la capacidad de disminuir la formación de aductos, entre otros (Ulbricht et al., 2010).

Los resultados obtenidos en el presente trabajo demuestran que el extracto de romero tiene la capacidad de actuar contra una bacteria de interés en medicina veterinaria como el $S$. aureus, y de impedirle (aún a concentraciones subinhibitorias) la producción de biopelícula. Este aspecto es sumamente importante si consideramos que una de las posibles causas por las que se producen infecciones crónicas, por ejemplo en la glándula mamaria de animales productores de leche, es justamente la capacidad de este microorganismo de generar biopelículas in vivo (Dubravka et al., 2010). Por otro lado, fue posible demostrar que el extracto de romero, a las mismas concentraciones que presenta actividad antimicrobiana, produce también un efecto protector del material genético, disminuyendo los niveles de daño en el ADN generados por la exposición a peróxido de hidrógeno. Teniendo en cuenta lo expuesto, se hace necesario continuar investigando la capacidad antimicrobiana del extracto de romero contra bacterias productoras de mastitis, con la finalidad de evaluar la posibilidad de emplear el extracto de romero in vivo en forma local para el tratamiento de infecciones crónicas relacionadas con la presencia de biopelícula.

\section{Agradecimientos}

Este trabajo fue financiado por la Secretaría de Ciencia y Técnica de la Universidad Nacional de Río Cuarto, Res. Rectoral 344/15.

\section{Conflicto de intereses}

Los autores declaran que no existe conflicto de intereses, incluyendo entre estos últimos las relaciones financieras, personales o de otro tipo con otras personas u organizaciones que pudieran influir de manera inapropiada en el trabajo. 


\section{Bibliografía}

Aboelmaaty AM, Mansour MM, Ezzo OH, Hamam AM. 2008. Some reproductive and metabolic responses to food restriction and re-feeding in Egyptian native goats. Global Veterinaria. 2:22532.

Afonso MS, de O Silva AM, Carvalho EB, Rivelli DP, Barros SB, Rogero MM, Lottenberg AM, Torres RP, Mancini-Filho J. 2013. Phenolic compounds from rosemary (Rosmarinus officinalis L.) attenuate oxidative stress and reduce blood cholesterol concentrations in diet-induced hypercholesterolemic rats. Nutrition and Metabolism (Londres). 10:19-25.

doi: 10.1186/1743-7075-10-19

Aherne A, Kerry J, O'Brien N. 2007. Effects of plant extracts on antioxidant status and oxidantinduced stress in Caco-2 cells. British Journal of Nutrition. 97:321-28.

doi: 10.1017/Sooo7114507250469

Avila-Sosa R, Navarro-Cruz AR, Vera-López O, Dávila-Márquez RM, Melgoza-Palma N, MezaPluma R. 2011. Romero (Rosmarinus officinalis): Una revisión de sus usos no culinarios. Ciencia y Mar. 52:23-6.

Balouiri M, Sadiki M, Ouedrhiri W, Farah A, Abed SEl, Koraichi SI. 2014. Antibacterial activity of extracts from Salvia officinalis and Rosmarinus officinalis obtained by sonication and maceration methods. International Journal of Pharmacy and Pharmaceutical Sciences. 6:167-70.

Borges A, Abreu AC, Dias C, Saavedra MJ, Borges F, Simões M. 2016. New perspectives on the use of phytochemicals as an emergent strategy to control bacterial infections including biofilms. Molecules. 21 (7):1-41.

doi: $10.3390 /$ molecules21070877

Brendler-Schwaab SY, Schmezer P, Liegibel U, Weber S, Michalek K, Tompa A, Pool-Zobel BL. 1994. Cells of different tissues for in vitro and in vivo studies in toxicology: Compilation of isolation methods. Toxicology in Vitro. 8:1285-302.

doi:10.1016/0887-2333(94)90122-8

Buege JA, Aust SD. 1978. Microsomal lipid peroxidation. Methods in Enzymology. 52:302-10.

Celi P, Gabai G. 2015. Oxidant/antioxidant balance in animal nutrition and health: the role of protein oxidation. Frontiers in Veterinary Sciences. 2:1-13. doi: 10.3389/fvets.2015.00048

Ceylan O, Ugur A, Sarac N, Ozcan F, Baygar T. 2014. The in vitro antibiofilm activity of Rosmarinus officinalis L. essential oil against multiple antibiotic resistant Pseudomonas sp. and
Staphylococcus sp. Journal of Food, Agriculture \& Environment. 12:82-6.

Clinical and Laboratory Standard Institute. 2012. Methods for Dilution Antimicrobial Susceptibility Tests for Bacteria That Grow Aerobically; Approved Standard $-9^{\circ}$ Ed., Wayne, Pennsylvania.

Dubravka M, Lazic S, Branka V, Jelena P, Bugarski D, Zorica S. 2010. Slime production and biofilm forming ability by Staphylococcus aureus bovine mastitis isolates. Acta Veterinaria Brunensis. 60:217-26.

doi: 10.2298/AVB1003217M

Fox LK, Zadoks RN, Gaskins CT. 2005. Biofilm production by Staphylococcus aureus associated with intramammary infection. Veterinary Microbiology. 107:295-9.

doi: 10.1016/j.vetmic.2005.02.005

Freshney RI. 2000. Culture of animal cells: a manual of basic technique, $4^{\circ}$ Ed. Wiley.

Genena AK, Hense H, Smania Junior A, de Souza SM. 2008. Rosemary (Rosmarinus officinalis) - a study of the composition, antioxidant and antimicrobial activities of extracts obtained with supercritical carbon dioxide. Ciência e Tecnologia de Alimentos. 28:463-9.

doi: 10.1590/So101-20612008000200030

Issabeagloo E, Kermanizadeh P, Taghizadieh M, Forughi R. 2012. Antimicrobial effects of rosemary (Rosmarinus officinalis L.) essential oils against Staphylococcus spp. African Journal of Microbiology Research. 6:5039-42.

doi: 10.5897/AJMR12.741

Klancnik A, Guzej B, Kolar MH, Abramovic H, Mozina SS. 2009. In vitro antimicrobial and antioxidant activity of commercial rosemary extract formulations. Journal of Food Protection. 72:1744-52.

doi: 10.4315/0362-028X-72.8.1744

Lykkesfeldt J, Svendsen O. 2007. Oxidants and antioxidants in disease: oxidative stress in farm animals. Veterinary Journal. 173:502-11.

doi: 10.1016/j.tvjl.2006.06.005

Marcincak S, Sokol J, Turek P, Rozanska H, Dicakova Z, Mate D, Popelka P, Korim P. 2003. Comparative evaluation of analytical techniques to quantify malondialdehyde in broiler meat. Bulletin of the Veterinary Institute in Pulawy. 47:491-6.

Martín Zurro A. 2004. Efecto del uso de ultrasonidos en la extracción de plantas labiadas combinando etanol y $\mathrm{CO} 2$ supercrítico. Atención Primaria. 34 (8):1-46. 
Santoyo S, Cavero S, Jaime L, Ibañez E, Señoráns FJ, Reglero G. 2005. Chemical composition and antimicrobial activity of Rosmarinus officinalis L. essential oil obtained via supercritical fluid extraction. Journal of Food Protection. 68:790-5. doi: 10.4315/0362-028X-68.4.790

Sasirekha BM, Megha DS, Sharath M, Soujanya R. 2015. Study on effect of different plant extracts on microbial biofilms. Asian Journal of Biotechnology. 7:1-12.

doi: 10.3923/ajbkr.2015

Singh NP, McCoy MT, Tice RR, Schneider EL. 1988. A simple technique for quantitation of low levels of DNA damage in individual cells. Experimental Cell Research. 175:184-91. doi: 10.1016/0014-4827(88)90265-0

Toyang NJ, Ateh EN, Keiser J, Vargas M, Bach H, Tane P, Sondengam LB, Davis $\mathrm{H}$, Bryant $\mathrm{J}$, Verpoorte R. 2012. Toxicity, antimicrobial and anthelmintic activities of Vernonia guineensis Benth. (Asteraceae) crude extracts. Journal of Ethnopharmacology. 144:700-4.

doi: 10.1016/j.jep.2012.10.016

Ulbricht C, Abrams TR, Brigham A, Ceurvels J, Clubb J, Curtiss W, Kirkwood CD, Giese N, Hoehn $\mathrm{K}$, Iovin $\mathrm{R}$, Isaac $\mathrm{R}$, Rusie $\mathrm{E}$, Serrano JMG, Varghese M, Weissner W, Windsor RC. 2010. An evidence-based systematic review of rosemary (Rosmarinus officinalis) by the Natural Standard Research Collaboration. Journal of Dietary Supplements. 7:351-413.

doi: 10.3109/19390211.2010.525049

Vu B, Chen M, Crawford RJ, Ivanova EP. 2009. Bacterial extracellular polysaccharides involved in biofilm formation. Molecules. 14:2535-54. doi: 10.3390/molecules14072535 